\title{
Utilization of huffman coding for weather buoy system using long-range communication
}

\author{
Jessica S. Velasco ${ }^{*}$, Mariela Credo ${ }^{1}$, Abeille Mae P. Salazar ${ }^{1}$, Shirleen Rence S. De Ocampo ${ }^{1}$, Venice \\ Julliane C. Enriquez ${ }^{1}$, Maria Victoria C. Padilla ${ }^{1}$, Edgar A. Galido ${ }^{1}$, Nilo M. Arago ${ }^{1}$, Glenn C. Virrey ${ }^{1}$ \\ and Lean Karlo S. Tolentino ${ }^{1,2}$
}

Electronics Engineering Department, Technological University of the Philippines, Manila, Philippine $\mathrm{s}^{1}$

University Extension Services Office, Technological University of the Philippines, Manila, Philippines ${ }^{2}$

Received: 30-April-2021; Revised: 25-June-2021; Accepted: 27-June-2021

(C2021 Jessica S. Velasco et al. This is an open access article distributed under the Creative Commons Attribution (CC BY) License, which permits unrestricted use, distribution, and reproduction in any medium, provided the original work is properly cited.

\begin{abstract}
Weather buoy is an instrument used to gather weather and ocean parameters and is deployed in the world's ocean. Monitoring sensors are used for gathering weather and ocean parameters. The data is transmitted through long-range (LoRa) communication system. Transmission in a weather buoy is conventional by sending non-compressed input data, or via digital signal processing that compresses and decompresses the gathered data in a real-time transmission. In this paper, the Huffman Coding algorithm was used for minimizing and compressing codes. It was utilized to ensure the transmission of digital data from the transmitter of the weather buoy to the receiver part. The fixed-length codes with different bit numbers generated by the transmitter reduced the length of the messages from an average of 2000 bits per second to 480 bits per second per message through the use of the Huffman Coding algorithm. The evaluated result consists of 125 transmissions and encountered 7 non-compressed data. Therefore, the text file compression or the accuracy is $118 / 125$ or 94.4\%. The Huffman Coding approach was found to be an optimal solution for data transfer as it can transmit compressed input data. It is about 13 seconds compared to a 6-minute time delay with occurrences of data traffic. It is for the data which are non-compressed and transmitted as it is. It shows significant improvement in the real-time transmission and monitoring, especially for weather system.
\end{abstract}

\section{Keywords}

Huffman coding, Digital signal processing, LoRa, Compress, Decompress, Digital data.

\section{Introduction}

Weather defines the short-term condition of the atmosphere in a certain region, while climate is the statistical weather condition at a given place during a specified period of time. Climate change describes the change of weather patterns over time within the range of decades to millions of years. According to studies, earth is experiencing climate change due to human activities. This past decade, predicting the weather condition has become a tough problem that humans encounter everywhere around the world. This sometimes results in an inaccurate weather prediction. But in order to predict and lessen the possibilities that risk and harm people's lives, developing marine weather information like buoys is done. Deploying weather buoys in the ocean helps predict weather conditions in a specific location in real-time. It is used to monitor the conditions of the ocean's surface and deep below it.

*Author for correspondence

685
The buoys also help to forecast natural phenomena such as earthquakes and storms by using sensors to gather different parameters such as air temperature, air density, relative humidity, wind speed, rainfall, solar radiation, water temperature and salinity profile [1].

In predicting weather conditions, deploying weather buoy can now be deployed together with Wireless Sensor Networks (WSNs). WSNs are used in different areas of technology involving environment monitoring, medicine fields, logistics, etc. New Internet of Things (IoT) innovations, such as Long Range (LoRa), is evolving, allowing for very long wavelengths of power-efficient wireless connectivity [1].

LoRa is a technology is rapidly turning up and is used because of its technical advantages such as the lifetime of battery, long range, security and more [2]. LoRa has a good resistance to interference and provides 
adequate network coverage up to $3 \mathrm{~km}$ in a residential area [3].

LoRa and Long-Range Wide Area Network (LoRaWAN) were extensively used in different implementations and applications. These are used in healthcare applications which help to supervise the vital signs monitoring of the patient, especially in farflung areas [4, 5]. These were also applied as successful transmission modes in precision aquaculture, whether intensive or extensive in the form [6-8] and in Aquaponics [9] for easy and faster checking and verification of plant, water, and fish parameters.

In digital communications, data compression is critical for quicker and more reliable delivery. As a result, prior to transmission, the data are subjected to source encoding called data compression, which is the method of compressing the data into smaller bits. Source encoding is also important for data storage to restrict the file sizes [10]. Data representation or graphic representation techniques mark at the heart of computer science and Huffman's research a crucial breakthrough in finding successful ways to represent information. Huffman 's seminal paper has accrued more than the 7,500 citations since its publication in 1952 and has inspired many of the compression and coding systems that are commonly used in devices today $[11,12]$.

One of the main objectives of this study is to create a network and collect data from different monitoring sensors wirelessly. The data collected from the sensors placed inside the buoy are monitoring meteorological and hydrological parameters in the open sea. The study also includes the organization and the availability of the server. There are three buoys each consis ts of eight different monitoring sensors in the open sea. The buoy is also called Weather Buoy as it has the capability to collect data that are vitals in weather prediction.

To gather data from the sensors, we constructed a contact network for the three weather buoys. The two methods of transferring data from the sensors to the receiving end are (1) non-compressed and (2) compressed data using Huffman coding. These methods are compared to evaluate the advantage of using Huffman coding and determine its benefits in long-range communication for weather buoys.

One of the challenges is the distance of the weather buoys to the Base Station (BS). In order to achieve accurate data for weather prediction, the weather buoys must be deployed in different parts of the sea (certain location). The approximate distance is not less than 750 meters away from the shore. There is an inadequate communication technology that covers that much range wirelessly. This result in the utilization of the communication technology, LoRa is now gaining popularity in the industry of WSN. This study does not cover the design and construction of the weather buoy and also the interpretation of weather based from the data gathered.

\section{Literature review}

In the past years, the WSN materialized as one of the most essential wireless network fields of research. Randomly, the sensors are located in an area, and each node detects its environment and transmits the accumulated data to the Cluster Head $(\mathrm{CH})$, that accumulates and sends the information procured to the Base Station (BS). The most significant parameters in WSN concerned for $\mathrm{CH}$ selection are energy, delay and distance [13].

Doloi et al. [14] used CC2500 Radio Frequency (RF) modem as a transceiver module which is a straightforward communication at $2.4 \mathrm{GHz}$, and a short distance module which is not a problem for this study doesn't require long range. It also used star topology, and the difference is the data gathered is not sizable enough to cause slower transmission, thus doesn't require digital signal processing.

San-Um et al. [15] presented a technology for IoT called Universal and Ubiquitous Long Range (ULoRa) and utilized it in tactical troop tracking systems. The said technology is connected through Wi-Fi for a communication with the server and can be combined with different types of sensors. The system's LoRa module is linked to an Arduino Pro-Mini, which manages the input and output data collected. Moreover, the U-LoRa End-Nodes applied in the system are used to transmit data through LoRa Gateway to the network switch which is under the IoT and the web server. The gathered data transmitted to the network was visualized real-time through the graphic user interface.

To determine the applicability of wireless industrial networks, the LoRa radios built by Semtech Corporation and the LoRaWAN technology were assessed [16]. It seems that it is built for Io T and meet the requirements of the industrial environments.

Rizzi et al. [17] suggested a wireless communication device to locate a fishery buoy. The device used LoRa 
contact technologies. Experimental findings revealed that the global positioning site location of the buoy could be shifted to a fishing boat in a bay of around 15 $\mathrm{km}$. Furthermore, if a lithium-ion battery is utilized, the unit operates continuously for a year.

As the world advances in technology, data is becoming the core of relevance in scientific research and studies. Storage and data retrieval play an important role in it. Fortunately, storages nowadays are effective and inexpensive, it no longer causes restraints in data retrieval. The problem in the database is how to advance the query and make it more precise [18].

Automated weather station (AWS) technology is seen in other countries' weather bureau because of its precise and accurate data. There are many ways on how to transmit data using an AWS namely: Zigbee, Short Message Service (SMS), Multimedia Message Service (MMS) or Global Positioning System (GPS). With the use of SMS, users could view the data by requesting or sending a specified keyword to the system. The software components are the Apache Web server, MySQL Database and PHP Scripts. Apache was then viewed the output of the web application using MySQL and PHP scripts [19].

Zhang et al. [20] suggested that the Huffman coding is the simplest to achieve and has a higher compression efficiency compared to the run-length encoding and Lempel-Ziv-Welch encoding. This compression technique helps to increase the effectiveness of the data transmission and condenses the operating time of the system. Thus, Huffman coding is applied in the field-programmable gate array of the hardware system of the said study. Moreover, it shows that Huffman coding lessens the power consumptions of the system based on their accomplished data compression comparison.

Gopal et al. [21] shows that due to advances in electronics and wireless communication, small-scale sensor nodes had developed that include data processing, sensing, and communication components. WSN was deployed which is regarded as a notable improvement compared to conventional wired sensor networks. In the most part, sensor nodes are deployed in a potential unfavorable or even aggressive state. It is a small-scale device that is sensed and wireless capabilities. It has a lot of applications such as military, environmental, safety, home, and commercial.
While all these studies show the benefits of transmitting encoded data, another study shows the other side of data encryption. The study focuses on securing the data from risks [22]. Thus, it gives the study an unexpected support.

According to [23], WSNs with the self and auto configuration of nodes, as well as the ability to operate without human intervention, have enhanced efficacy and rendered this type of system easier to install and more flexible. The paper emphasizes on getting the humidity and temperature data from the forest. It employs WSN to capture data simultaneously out of each area in the forest. It employs the Zone-based Clustering $(\mathrm{ZbC})$ system to increase the network lifetime and decrease network latency.

Drawbacks of Wireless Sensor Networks are the importance of constructing a BS, its static character and centralized route. They depend on a stable connection for communication. Therefore Ad Hoc Networks is introduced. It does not need a base station and does not work in centralized routing, which makes it great as it is equally distributed routing. It gives the nodes the freedom to move around, and the topology can be easily changed. This effective quality of Ad Hoc Networks fits perfectly for demanding applications [24].

In [25] a low-cost wireless weather monitoring device that can be easily accessed by the public through the Internet was developed. The weather monitoring device consists of different kinds of sensors, including temperature and humidity, gas, noise, along with rainfall. These sensors collect figures and set the parameters for weather monitoring. The aim of the system is to help citizens choose the best environment for their living purpose.

WSNs is targeted for data monitoring with a variety of hypotheses. Average loss rates are important in network reliability, but high loss rates are also important in delivery since high time amounts in error with wireless connection found it infeasible to guarantee dependable control of the intended employment. Restrictive existing packet periods and traffic patterns on data monitoring are also one of the as sumptions in this study. New as sessment criteria are needed in order to assess the reliability of these networks. It discusses the reliability of the WSN for output tracking, suggests a system to enhance the fairness of the routes towards the center node as a move along local route technique, and test the 
recommended system via a qualified transmission ratio of data with wireless error [26].

In addition, it relies on the tracking of data to the WSN with the subsequent hypotheses. The application's perspective is collected with the reliability needed to sensed data from nodes. Hence, average loss and distributions are highly significant. As a matter of fact, despite having normal loss rates within the limits requested by the indicated apps, the verification of having no separate network devices with steep loss rates is important, as this would cause difficulty securing the stable operation of the intended applications. To successfully assess the balance of these networks, new interpretation metrics are therefore necessary. However, indicating that the ratios of packet distribution are a key metric to justify for WSNs.

The use of WSN serves a major role in monitoring the environment. This study shows that the use of WSN for monitoring sea route is crucial to ensure the nearby ships' safety. A data compression algorithm was proposed which is called Adaptive Time Piecewise Constant Vector Quantization (ATPCVQ). It is able to improve the data transmission of the sea route as well as the survivability of the network's system and capable of enhancing the lifespan of the sensor nodes. ATPCVQ successfully lessens the redundancy of spatial and time to approach a compression ratio within the allowable deviation of $18 \%$. The expected data compression algorithm proved to be efficient by the illustration and verification using the actual output gathered from the buoy at Qinhuangdao Port of China [27].

There are many ways to monitor the environment using different technologies to implement WSN. In this case, Zigbee technology was used as the wireless communication module and tree-topology which is able to transmit data without interruption. According to this study the tree-topology consis ts of a base station and two sensor nodes. The two nodes are made up of various sensors to monitor the greenhouse gasses and Zigbee transmitter while the base station consists of Zigbee receiver, an Arduino UNO microcontroller and a Wi-Fi_33 module for wireless communication over the $802.11 \mathrm{~b} / \mathrm{g}$ wireless networks. A website was developed to display the data online and have access in real time, it was executed with the use of a graphical Application Programming Interface (API) wherein the gathered data is inserted into a MyQSL database which is one of the tools used to implement the website [28].
The transmitters transfer an arbitrary frequency within the upper and lower bandwidth. Hence, a softwaredefined radio receiver capable of receiving a full range of frequency was used. Accordingly, it takes the particular nodes, then filter it despite the multiple nodes that are transmitted simultaneously. A concurrent multi-channel receiver is made. The data rate of the transmitter is small, this results in a small bandwidth in which corresponds to an extremely high sensitivity [29].

A low-cost crystal os cillator with Asynchronous Shift Keying (ASK) to replace the radio chip was developed [29]. For the oscillator and the power amplifier, two individual voltage regulators were used. It designed the transmitter to generate a reliable signal that has low phase noise to maintain low bandwidth. It is loaded the crystal with capacitances for tuning to add a frequency offset so that the two transmitting nodes do not interfere with one another because of a sufficient frequency difference [29]. Two single sideband receivers that modify the ASK signal to an audio signal were employed. Using digital signal processing, it filters and demodulates the audio signal. A low-cost, reliable multi-transmitter and multi-channel receiver for a WSN applying Ultra-High Frequency (UHF) radios was developed.

According to this study [30], the sensors of the network were established that shall monitor the characteristics of water like temperature, the dis solved oxygen, it's potential of hydrogen $(\mathrm{pH})$, etc., and supply different suitable assistance for the operation, the gathered data from a considerable distance in a console terminal via a website with spreadsheets. It introduced the layout of WSN's system, the construction of the node, it's data processing with gateway, data acquisition and data visualization. Measuring the characteristics of water in Kuwait, this project showed preferable solutions using special sensors. In addition, preprogramming the procedure of obtaining the qualities of water readings with a WSN systemwas presented. This study is cost effective built system in terms of budget, consumption of time and workforce.

A system was designed [31] for weather monitoring using different sensors that can be accessed through the internet. The data parameters were acquired through AWS and processed using serial communication. They used Weatherlink software with Windows 5.7.1 for data acquisition. This software is used for station configuration, the measurement setup of the component's unit, Internet configuration setup, 
and data gathering from the Vantage Pro or VP data logger console. In the format of HTML Extension (HTX) file is the kind of data gathered from the console and this is utilized to outline the display of the UI and short term store the data. The data in the form of an image are used to indicate the present condition of the weather data in 24 hours. They also made a mobile application where the web interface may be available in the form of an android application packet. All in all, a real-time weather monitoring system that is accessible on android mobile phones was developed.

A study [32] done in a weather monitoring system in a tough environment, reducing the damage of the disaster is one of the aims of a high-density weather monitoring system. On the 9th of June 2014, the Indian Meteorological Department (IMD) observed 48 degrees, which could affect the deployment of the AWS. Moreover, 19 AWSs were installed within 10 $\mathrm{km}$ square mesh to collect real time data since there are only 2 AWSs in Hyderabad City. AWS, which is linked to the Internet, transmits the data to the server. They have two matching servers where one server is located in the IIT or Indian Institute of Technology and the other one is in IMD. Since Indian Institute of Technology has two hours of power cut rolling every single day, their gathered data is synchronized to the server in IMD. Also, if the IMD has a problem, it can synchronize to Indian Institute of Technology Hyderabad City (IITH). This process avoids the interruption and delay of data since they have a difficult environment.

A study [33] focused on integrating the two concepts to simplify the environment around the user to make it interesting and relaxed. The system manages the environmental situation and get the home pleasant automatically. The method is accessible to individuals who are blind or disabled by means of a speech recognition technique. Based on the systemof weather monitoring, the system is automated which is a system that runs using the output of the weather monitoring system. It is also operated by using a cell phone if the consumer wants a setting. The goal of the study is a successful, cost-effective prototype and an automated smart home system.

In this study [34], the a unidalog advanced systemwas used as broadcasting structure at each monitoring system for output gathered from the data logger. The system facilitates data integration from various data structures of tracking weather and tides. The gathered data are coordinated in a data center. For this research, it used Data Warehouse (DW) technique for the integration of gathering weather monitoring data from the systems. This technique is a straightforward solution integrating data and is efficient for constructing extensible, flexible and cost-effective central data. The DW technique also permits merging of transmitting information and data collection from different data systems. Furthermore, a weather monitoring system gathers the data for monitoring stations collected and information is placed in a relational database.

This study [35] focuses on the idea of being informed with the availability of accessible parking vacancy in a parking lot using the IOT Technology. Based on the study, not enough parking spaces cause traffic jams nowadays. According to this study, IoT is very important in associating ecological things that surround the people to a network. It enables the researchers to screen the limitations of things using sensors that are familiar with distant detecting of a particular information and send in the data on cloud organization through methods for web access. Numerous smart cities encounter problems with parking issues can benefit from this study.

This research [36] proposes a solid design of a network that observes the patients with mental disorders and studies them through a designed system using the LoRa IoT. By using cellular phones and Wi-Fi connections as the communications media, the local and cloud servers are linked to the LoRa gateways. The researchers presented a deliberation concerning the practicality of the performance of the LoRa network, scalability and power battery. The proposed design became feasible with the advantages of LoRa. Building and testing the scenarios using the real system is to be done in the future.

According to this study [37] through the use of a multilevel relay and a LoRa communication concentrator, a remote reading meter system was proposed. The ST's low-energy microcontroller (STM81151 G) was selected to monitor the SX1278 and to calculate the flow to fulfill the extremely low power needs of the meter. Their device has achieved precise measurements of the water meter count, then it forwards the data using a multi-level LoRa relay to the concentrator. A smart water meter, a multi-level relay, and a concentrator are what made a wireless meter reading network, which is used for data management and transmission. In addition, Lora technology allows a broader range of transmissions and distances with low transmitting power. 
In [38], LoRa technology is used as an application for driving safety. LoRa-based Low Power Wide Area Network (LPWAN) vehicle diagnostic system which consists of LoRa gateway and module, an Arduino UNO, and a remote diagnostic system which has an On-board diagnostics (OBD)-II in a vehicle called icar system. In detecting abnormal vehicle information, the OBD-II Bridge is in-charge of this. Through the LoRa module and Arduino, the LoRa gateway was immediately received all the information about the abnormal events in vehicles. Moreover, the cloud platform received the information from the LoRa gateway, and this platform was used for recording the abnormalities in vehicles via Ethernet. Also, the gathered information from the cloud platform also be filtered to reduce the bandwidth and the usage of energy from the smartphone. Due to this recording, the vehicle maintenance plant may inform and can actively give necessary assistance or maintenance check-up for vehicles to achieve driving safety.

This study [39] aims to have a remote sensor network underneath the ground with the application of LoRa technology for this type of network system has been widely evolved and studied for the past few years. Because of the advantages of the WSN, the wireless underground sensor network (WUSN) became the latest network and gets the attention of the researcher. This network consists of wireless underground sensors which transmit and receive information or commands in the soil. The study is performed in an ordinary municipal garden and an ordinary farmland is chosen for the estimations

This study [40] focuses on providing a safe and comfortable wireless communication system by having a thorough research and establishing ecofriendly and disaster-resilient green base stations. The researchers succeeded to form a Photovoltaic system (PV system) that was able to sustain the remaining time once a power interruption occurs for base stations as one of means of disaster measure in carriers. The power control method has been presented as a method that perceives a lengthy self-sufficient operation through PV and Lithium-Ion Batteries (LiB) and rebuilding performance through PV to withstand an economic power loss during a power outage along with the report of the outcome acquired at the station. This paper defined the fulfillment of the environmental benefits and a disaster awareness in a green base station on a Weathercast-linked control.

In [41] configured and tentative outcomes of a new wideband dual-polarized central station antenna was discussed with greater efficiency. The researchers suggested an antenna consisting of four electric folded dipoles which is positioned in an octagon form and each polarization is energized simultaneously. Including the four folded dipoles with greater performance, the dual-polarized antenna achieves all the measurements for the elements of the $4 \mathrm{G}$ base station antenna. This antenna utilizes four folded dipoles whereas these two specific feed networks emit signals to achieve the two radiation patterns. The proposed antenna is well-suited to the wideband from $1.69 \mathrm{GHz}$ to $2.71 \mathrm{GHz}$ based on the tentative outcomes for both the two polarizations. Also, without any alteration of the ground plane, constant radiation patterns are achieved. The wideband $\pm 45^{\circ}$ dualpolarized antenna portion is added to the base station including four folded dipoles energized simultaneously.

In [42], the base station sends data overseas with the use of a mobile switching center, and it also has terminals according to this study. The antenna is one of the most important components of a base station. The antenna is the part which is responsible for shifting the space radiation's electromagnetic wave and the communication device's electrical signals. The antenna consists of four segments which are the reflector, main radiator, bed frame, and feeding Baluns. The gathered outcomes in the antenna present an impedance bandwidth of $48 \%$ and reflection coefficient not more than $-15 \mathrm{~dB}$ with more than $22 \mathrm{~dB}$ of port isolation. The researchers investigated a fourelement antenna array with $6^{\circ} \pm 2^{\circ}$ of electrical down incline for a utilization of a wide band base station. An array was improved synchronously with four antenna components. There are such advantages that can make the antenna a great contender for applications of Pico or wideband micro base station.

In [43] a procedure using Genetic Algorithms for mobile users to obtain the prearranged positions of base stations through the ideal position of the base station from virtual base station positions. The outcome of the simulation for performing the suggested procedure concerning the normalized network lifetime proves that the length of the network field is inversely proportional to the value for the normalized lifetime. They also consider the different forms of arrangements for subarrays and techniques for decoupling. There are also other aspects to remember when constructing antenna arrays.

Furthermore, the researchers [44] proposed a dualarray dual-band dual-polarized antenna which is 
applicable for low frequency band and high frequency band with an embedded system. Also, this antenna was implemented with a side-by-side system for the high frequency band consisting of subarrays with two columns. It attains a frequency band with a range of 1710-2170 MHz and Standing Wave Ratio (SWR) $<1.5$. Finally, a quad-array dual-band dual-polarized antenna consis ting of two columns of the subways was introduced for two low-frequency and two highfrequency bands for both side-by-side and integrated devices. Each subarray column is made up of two element arrays for high and low frequency bands, respectively. It has a range of $820-880 \mathrm{MHz}$ to 1710 $2170 \mathrm{MHz}$.

\section{Methods}

This section discussed and illustrate how the researchers develop the Huffman coding in the system and how it is used for compressing sensor data which can be compared with non-compressed data.

Huffman Coding is a technique used for generating prefix-free codes. It is an efficient source-coding algorithm and it produces the smallest number of code symbols possible for a single source symbol. It is an optimal lossless method of data compression. The symbols with high probability of occurrence are more emphasized in this process. This method of compression is efficient for data in which frequency of occurrence is high. Huffman coding has high optimization compared with Shannon Fano Coding. It also has better efficiency and produces optimal results, while optimal code generation is no ensured in Shannon Fano Coding. It is also prevalently used method for lossless text compression where compressed data can be stored in its original format. Unlike, Shannon Fano Coding that uses probabilities of the data to encode it.

If Huffman Coding is compared with Arithmetic Coding, it is the most important entropy compressor, Huffman codes are $\mathrm{F}$ to $\mathrm{V}$ block codes. It blocks the input into strings of q letters and encode these strings with variable length output strings. It uses a static table for the whole coding process, so it is faster. The relative efficiency of Huffman codes can be made as high as desired by taking the block size to be large enough. It also has low memory space and decompression speed is fast.

While in Arithmetic coding takes in an arbitrarily long input and output corresponding output stream. The encoding and decoding steps are too complicated to be done in real time. It is useful for small alphabets with highly skewed probabilities. The code word is not used to represent a symbol of the text. Instead, it produces a code for an entire message. Arithmetic algorithms can generate a high compression ratio, but its compression speed is low. The memory space is lower than Huffman, but the decompression speed is slow.

Figure 1 shows the transmitting process of the LoRa communication system using Huffman Coding Compression. The data gathered by the eight weather parameter sensors. It was then transformed into hexadecimal with assigned value after it passes through the Huffman coding compression for digital signal processing. This process reduces the bit size of the data and helpful to lessen the duration of the transmission. The compression ratio of the Huffman coding is up to $40 \%$.

Figure 2 shows the step-by-step procedure of data compression (encoding). The input message block in the figure consists of what is inside the Gray block. The input message is the collected raw data fromeight weather parameter sensors. From the input message, each weather parameter readings converted into hexadecimal values. The constants like the title and the unit were allocated to a certain hexadecimal value. The output message is in hexadecimal form. This process continues until all weather parameter readings are in hexadecimal form. Afterwards, it is transmitted to the database.

Figure 3 shows the process of data decompression after receiving it in the database. The input message now is the encoded data. The encoded data that consists of eight weather parameters, then converted to a decimal value. As shown in Figure 4, the transmitted hexadecimal data that is received by the LoRa Gateway is also in hexadecimal form. It appeared in the database logger before it undergoes the process of decompression. After it passes through the decoder, the data were transformed back into its original message. The data available in the parallel database are both in hexadecimal form and original form which are the weather parameter readings. The parallel database was also arranging the data in a proper table. It is used to identify the right weather parameter column.

Figure 5 shows the connection between the Arduino MEGA to Lora Transceiver Module. The Arduino MEGA collects and compress (encode) all the data from eight meteorological and hydrological sensors and the LoRa transceiver module. It transmits the compressed data. 
Jessica S. Velasco et al.

TRANSMITTING Process:

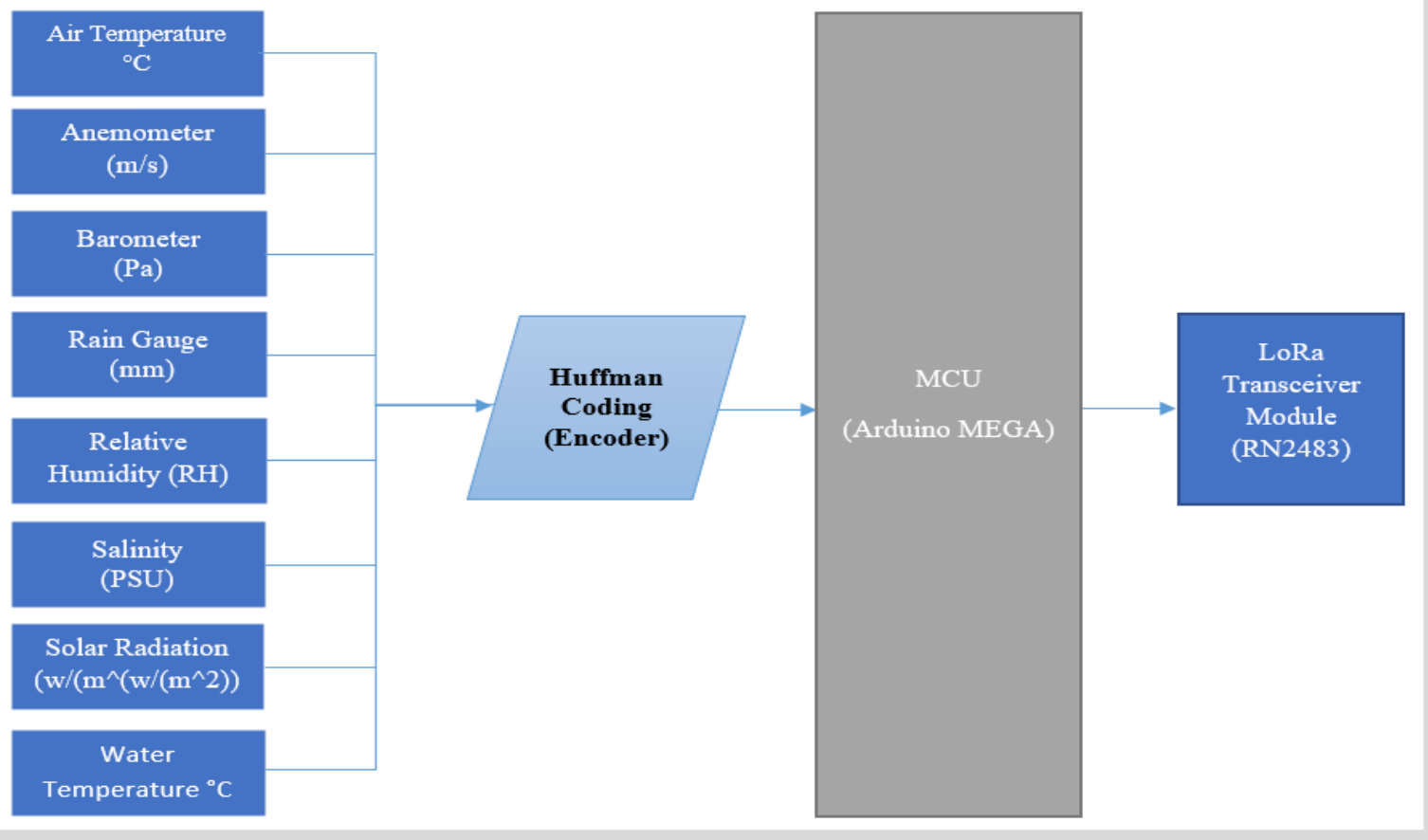

Figure 1 Transmitting process on the LoRa communication system using Huffman coding compression (Encoder)

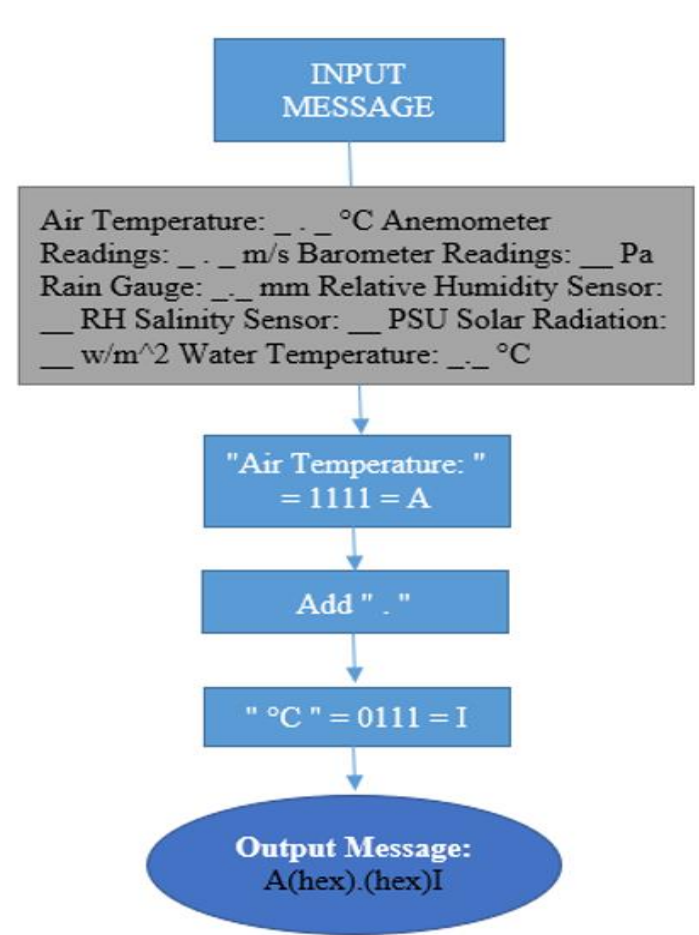

Figure 2 Sample compression process

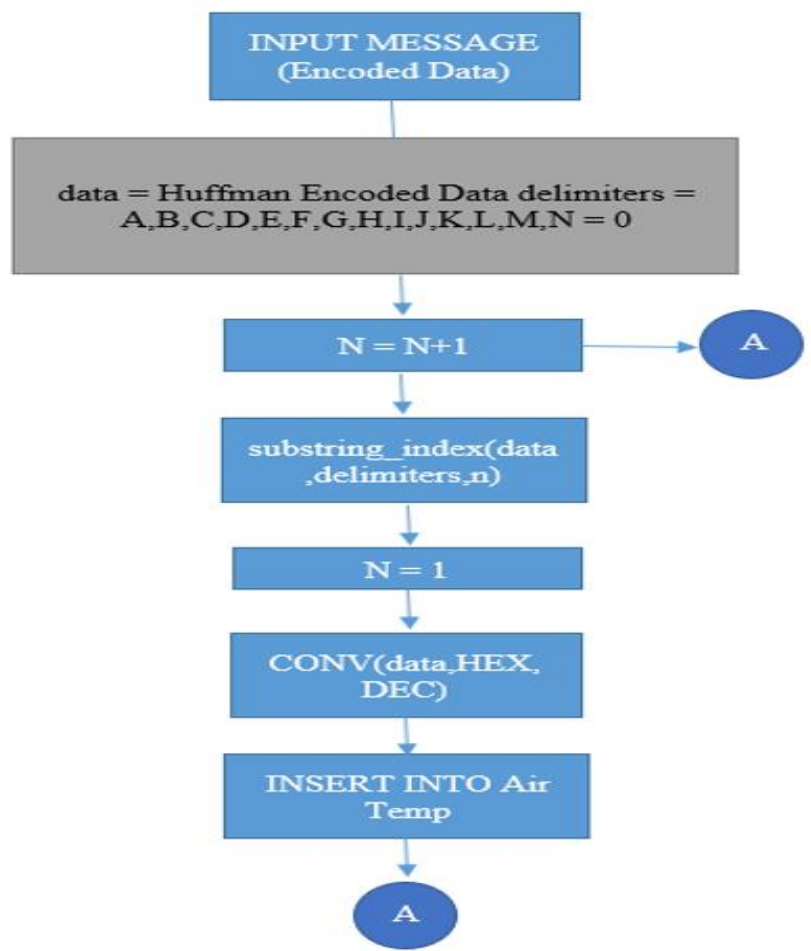

Figure 3 Sample decompression process 


\section{RECEIVING Process:}

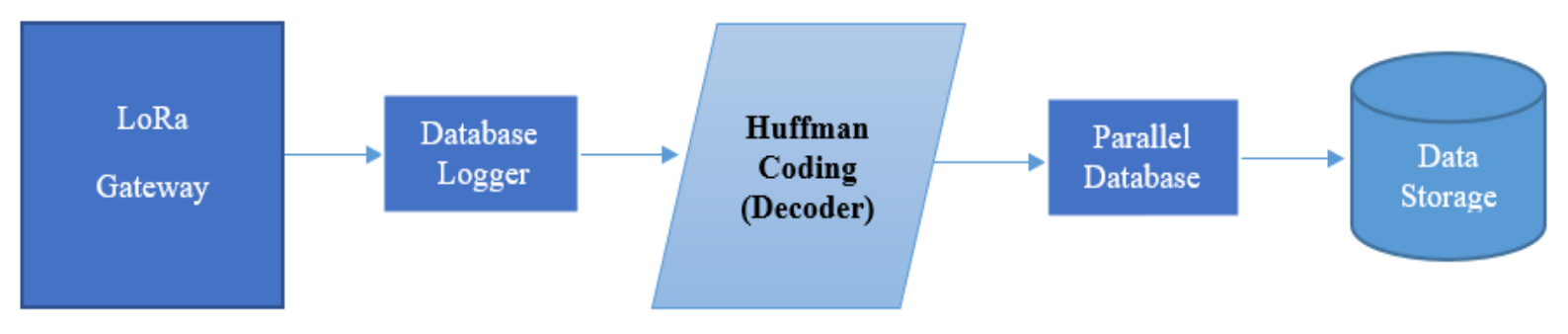

Figure 4 Receiving process on the LoRa communication system using Huffman coding decompression (Decoder)

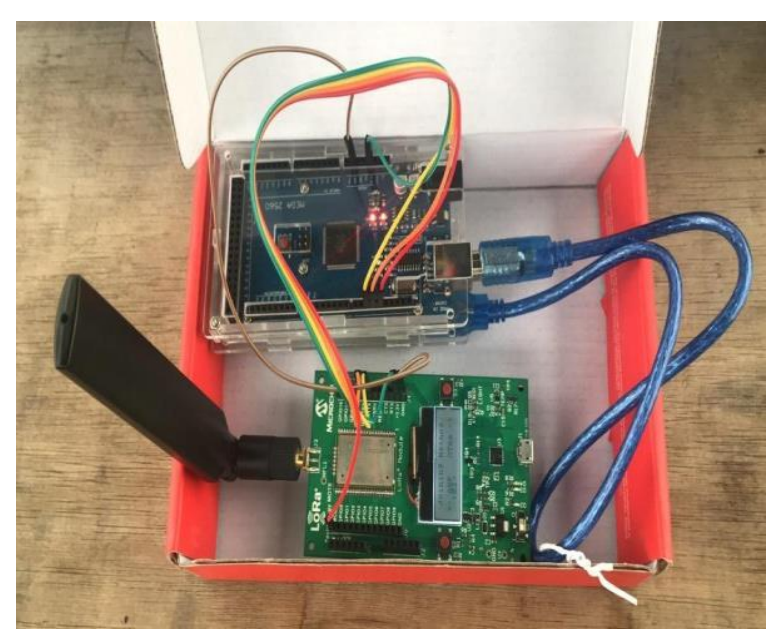

Figure 5 LoRa transceiver module (transmitter, color green) connected to Arduino MEGA (microcontroller unit, color blue)

\section{Results and discussion}

This section discussed the findings of the study. The researchers confirmed the results of the Huffman coding in the system and used for compressing sensor data and has encountered non-compressed data during transmission. The evaluated result consists of 125 transmissions and out of it there are 7 non-compressed data. The non-compressed and compressed data ratio of this study is $118 / 125$ or $94.4 \%$. Therefore, the accuracy of the study is $94.4 \%$.

Table 1 shows the collected data after the process of transmission. It also shows the received data that are non-compressed and the time delay. The results are significant as it shows the time of encounter of noncompressed data.

Table 2 shows the actual collected data that are successfully compressed. The evaluated result made 125 successful transmissions and out of these transmissions, it encountered 7 times non compressed data. The table also shows the Hexadecimal equivalent of the data received from the sensors of the weather buoy. The code transmitted the following parameters: Air Temperature in ${ }^{\circ} \mathrm{C}$, Anemometer in $\mathrm{m} / \mathrm{s}$, Barometer in Pascal, Rain Gauge in mm, Relative humidity in RH, salinity in Practical Salinity Unit (PSU), solar radiation at $\mathrm{w} / \mathrm{m}^{2}$ and water temperatures in ${ }^{\circ} \mathrm{C}$. It also shows the arrangement of the gathered data inside the database. The placement of the decoded data was properly assigned. The raw data were correctly decoded into a readable form. Not yet decoded HEX(Hexadecimal) data is represented by Unhexadecimal (UNHEX). Mote shows the transceiver module. Time shows the data received time. PSU shows the measure of salinity.

Table 1 Non compressed data tabulation

\begin{tabular}{llll}
\hline Number & Non-Compressed Data & Time (24-Hour format) & Time Difference (M) \\
\hline 1 & 3935392030323900 & $08: 13: 04$ & $00: 17: 39$ \\
2 & 3831312030323900 & $08: 30: 43$ & $00: 02: 43$ \\
3 & 3433392032303900 & $08: 33: 26$ & $00: 05: 34$ \\
4 & 3433392032303900 & $08: 39: 00$ & $00: 04: 08$ \\
5 & 3232332032303600 & $08: 43: 08$ & $00: 03: 21$ \\
6 & 3336352030323900 & $08: 46: 29$ & $00: 09: 33$ \\
\hline
\end{tabular}


Jessica S. Velasco et al.

Table 2 Evaluated result

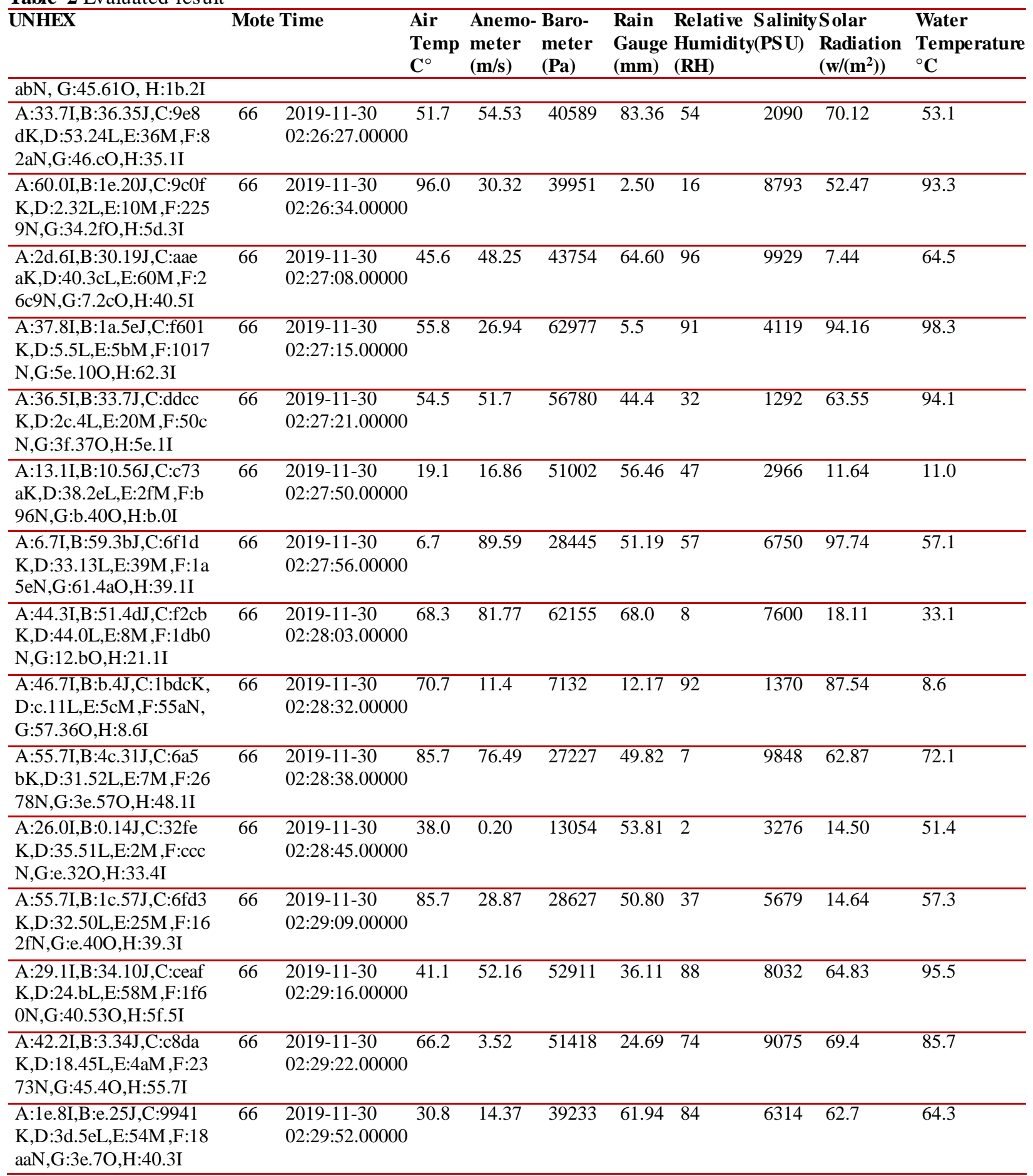

Table 3 shows the collected data after it went through the Huffman encoding algorithm. The encoder is located at the Arduino and the encoded data is in hexadecimal form which has an assigned value for every ASCII character. The LoRa transceiver automatically send the encoded or compressed data to the receiver through the LoRa Gateway. The data in hexadecimal form. It shows the successful application of encoding technique. It reduces the length of the message from an average length of 2000 bits per 
message to 480 bits per message. Table 4 shows the actual data received in the parallel database. The collected data went through the Huffman decoding algorithm. The decoder transformed the encoded data into its original form, since every ASCII character has an assigned value. It is easy to decode the encoded data. Once the data has been decoded, it is ready for interpretation. The table also shows the successful application of decoding technique. As it transforms the encoded data that is composed of hexadecimal value and ASCII characters to its original form of the message.

Table 5 and Table 6 shows the comparis on of the average delay time for the transmission of the compressed and non-compressed data, respectively. The non-compressed data were sent similarly as the compressed data. However, as seen in Table 4, it takes several minutes for it to be received on the other end. Not to mention, there are non-compressed input data that failed to reach the main base due to data traffic. It can be clearly seen on the average time delay of the data samples that it is better to compress the input data in order to be quickly received by the database. Unfortunately, the average time delay for compressed data using Huffman coding is not considered to be suitable for real-time monitoring.

Table 3 The data in hexadecimal form

\begin{tabular}{ll}
\hline Number & Message in Hexadecimal \\
\hline 1 & A:4c.7I,B:4d.53J,C:a98 2K,D:50.18L,E:2cM,F:1 ef3N,G:25.48O,H:11.6I \\
\hline 2 & A:47.0I,B:1d.22J,C:1d1 1K,D:61.25L,E:6M,F:c6 1N,G:2d.38O,H:4.6I \\
\hline 3 & A:39.1I,B:b.40J,C:8088 K,D:41.1dL,E:5cM,F:ffb N,G:33.55O,H:11.2I \\
\hline 4 & A:34.1I,B:37.17J,C:69c K,D:23.30L,E:31M,F:1e 2aN,G:34.1bO,H:8.8I \\
\hline 5 & A:49.0I,B:3f.60J,C:b89 5K,D:d.61L,E:19M,F:1f 4dN,G:f.3aO,H:44.0 \\
\hline 6 & A:50.5I,B:58.2aJ,C:29a eK,D:46.4eL,E:2M,F:c4 8N,G:42.2dO,H:b.5I \\
\hline 7 & A:5c.8I,B:40.5aJ,C:576 K,D:c.3bL,E:bM,F:2611 N,G:21.cO,H:e.7I \\
\hline 8 & A:34.8I,B:8.0J,C:4715K ,D:3c.37L,E:58M,F:175 0N,G:32.10O,H:37.6I \\
\hline 9 & A:18.1I,B:38.3bJ,C:b05 7K,D:62.2bL,E:8M,F:17 d2N,G:18.3O,H:27.2I \\
\hline 10 & A:61.5I,B:25.57J,C:9a5 bK,D:2f.14L,E:1aM,F:1 476N,G:49.60O,H:1d.7 I \\
\hline
\end{tabular}

Table 4 The data in original form

\begin{tabular}{ccccccccc}
\hline Time & $\begin{array}{c}\text { Air } \\
\text { Temperature } \\
\left({ }^{\circ} \mathbf{C}\right)\end{array}$ & $\begin{array}{c}\text { Anemometer } \\
(\mathbf{m} / \mathbf{s})\end{array}$ & $\begin{array}{c}\text { Barometer } \\
(\mathbf{P a})\end{array}$ & $\begin{array}{c}\text { Rain } \\
\mathbf{G a u g e} \\
(\mathbf{m m})\end{array}$ & $\begin{array}{c}\text { Relative } \\
\text { Humidity } \\
(\mathbf{R H})\end{array}$ & $\begin{array}{c}\text { Salinity } \\
(\mathbf{P S} \mathbf{)})\end{array}$ & $\begin{array}{c}\text { Solar } \\
\text { Radiation } \\
\left(\mathbf{w} /\left(\mathbf{m} \mathbf{m}^{\wedge}\right)\right.\end{array}$ & $\begin{array}{c}\text { Water } \\
\text { Temperature } \\
\left({ }^{\circ} \mathbf{C}\right)\end{array}$ \\
\hline $12: 24: 34$ & 76.7 & 77.83 & 43394 & 80.24 & 44 & 7923 & 37.72 & 17.6 \\
\hline $12: 24: 41$ & 71 & 29.34 & 7441 & 97.37 & 6 & 3169 & 45.56 & 4.6 \\
\hline $12: 25: 06$ & 57.1 & 11.64 & 32904 & 65.29 & 92 & 4091 & 51.85 & 17.2 \\
\hline $12: 25: 13$ & 52.1 & 55.23 & 1692 & 35.48 & 49 & 7722 & 52.27 & 8.8 \\
\hline $12: 25: 19$ & 73 & 63.96 & 47253 & 13.97 & 25 & 8013 & 15.58 & 68 \\
\hline $12: 25: 47$ & 80.5 & 88.42 & 10670 & 70.78 & 2 & 3144 & 66.45 & 11.5 \\
\hline $12: 25: 53$ & 92.8 & 64.9 & 1398 & 12.59 & 11 & 9745 & 33.12 & 14.7 \\
\hline $12: 26: 00$ & 52.8 & 8 & 18197 & 60.55 & 88 & 5968 & 50.16 & 55.6 \\
\hline $12: 26: 27$ & 24.1 & 56.59 & 45143 & 98.43 & 8 & 6098 & 24.3 & 39.2 \\
\hline $12: 26: 34$ & 97.5 & 37.87 & 39515 & 47.2 & 26 & 5238 & 73.96 & 29.7 \\
\hline
\end{tabular}

Table 5 Time delay of the collected, compressed databefore being received at the main base

\begin{tabular}{llll}
\hline Number & Non-compressed data & Time (24 Hour Format) & Time difference (m) \\
\hline 1 & 3935392030323900 & $08: 13: 04$ & \\
\hline 2 & 3831312030323900 & $08: 30: 43$ & $00: 17: 39: 00$ \\
\hline 3 & 3433392032303900 & $08: 33: 26$ & $00: 02: 43: 00$ \\
\hline 4 & 3433392032303900 & $08: 39: 00$ & $00: 05: 34: 00$ \\
\hline 5 & 3232332032303600 & $08: 43: 08$ & $00: 04: 08: 00$ \\
\hline 6 & 3336352030323900 & $08: 46: 29$ & $00: 03: 21: 00$ \\
\hline & 3232332030323700 & $08: 56: 02$ & $00: 09: 33: 00$ \\
\hline
\end{tabular}


Table 6 Time delay of the collected non-compressed data before being received at the main base

\begin{tabular}{lll}
\hline Number & Time (24 Hour Format) & Time difference (s) \\
\hline 1 & $12: 24: 34$ & \\
\hline 2 & $12: 24: 41$ & $0: 00: 07: 00$ \\
\hline 3 & $12: 25: 06$ & $0: 00: 25: 00$ \\
\hline 4 & $12: 25: 13$ & $0: 00: 07: 00$ \\
\hline 5 & $12: 25: 19$ & $0: 00: 06: 00$ \\
\hline 6 & $12: 25: 47$ & $0: 00: 28: 00$ \\
\hline 7 & $12: 25: 53$ & $0: 00: 06: 00$ \\
\hline 8 & $12: 26: 00$ & $0: 00: 07: 00$ \\
\hline 9 & $12: 26: 27$ & $0: 00: 27: 00$ \\
\hline & $12: 26: 34$ & $0: 00: 07: 00$ \\
\hline
\end{tabular}

Table 7 shows the comparison from the previous study. It shows that Huffman coding has a highest compression ratio of $94.4 \%$.

The result is based on the 125 transmissions and encountered 7 non-compressed data for the evaluation. The pros and cons of each previous work compared to this study are as under.

Pros:

The application of Huffman Coding in Julia Language can be easily navigated and understood by the users [14]. The benefits of applying Huffman Coding in a Data Acquisition (DAQ) system are low power consumption, the high effectivity rate of transmission, and shortens the processing time [19]. Compressive sensing algorithm reduces the collected data while maintaining the stable signal established. The reduced data helps in reducing the consumption of power in the nodes [20]. The application of Huffman Coding in Arduino Language saves a lot of storage space and can be easily navigated and understood. The Huffman algorithm can also accelerate the bit rate while the data is being transmitted using the LoRa transceiver motes.
Furthermore, the compression ratio has the significant lesser average time delay compared to data that are not compressed.

\section{Cons:}

It only serves as a learning material for compression and decompression techniques of Huffman Coding [14]. The use of Huffman Coding for data transmission proves its high efficiency in this study, however the project does not support real-time simultaneous data collection, which is not ideal for weather monitoring buoys [19]. This previous statement is evident based on the average time delay of the collected, compressed data using Huffman Coding before being received at the main base as shown in Table 5. The data are collected using transmitting signals. The representation of data can be widely affected as the signals can be unestablished. This results in ineffective data transmission and not suited for long distances [20].

Figure 6 shows the actual designed network topology used for the communication of the three weatherbuoys deployed in Manila Bay. The design is based on Star Topology, in which the LoRa communication technology works best.

Table 7 Comparis on between previous works and this work

\begin{tabular}{|c|c|c|c|c|}
\hline & This work & [14] & [19] & {$[20]$} \\
\hline Year & 2021 & 2016 & 2019 & 2016 \\
\hline Compression technique & Huffman Coding & Huffman Coding & Huffman Coding & $\begin{array}{l}\text { Compressive Sensing } \\
\text { Technique }\end{array}$ \\
\hline Software & $\begin{array}{ll}\begin{array}{l}\text { Arduino } \\
\text { phpMy Admin }\end{array} & \text { IDE, } \\
\end{array}$ & Jupy ter Notebook & - & - \\
\hline Algorithm & Huffman Algorithm & $\begin{array}{l}\text { Huffman } \\
\text { Algorithm }\end{array}$ & Huffman Algorithm & $\begin{array}{l}\text { Compressive Sensing } \\
\text { Algorithm }\end{array}$ \\
\hline Language & Arduino, MySQL & Julia & - & - \\
\hline Database & phpMyAdmin & None & None & None \\
\hline Data Display & Graphic User Interface & - & - & - \\
\hline $\begin{array}{l}\text { Text files compression / } \\
\text { Accuracy }\end{array}$ & $94.4 \%$ & $\begin{array}{l}\text { Very little or no } \\
\text { compression at all }\end{array}$ & $49.95 \%$ & - \\
\hline
\end{tabular}




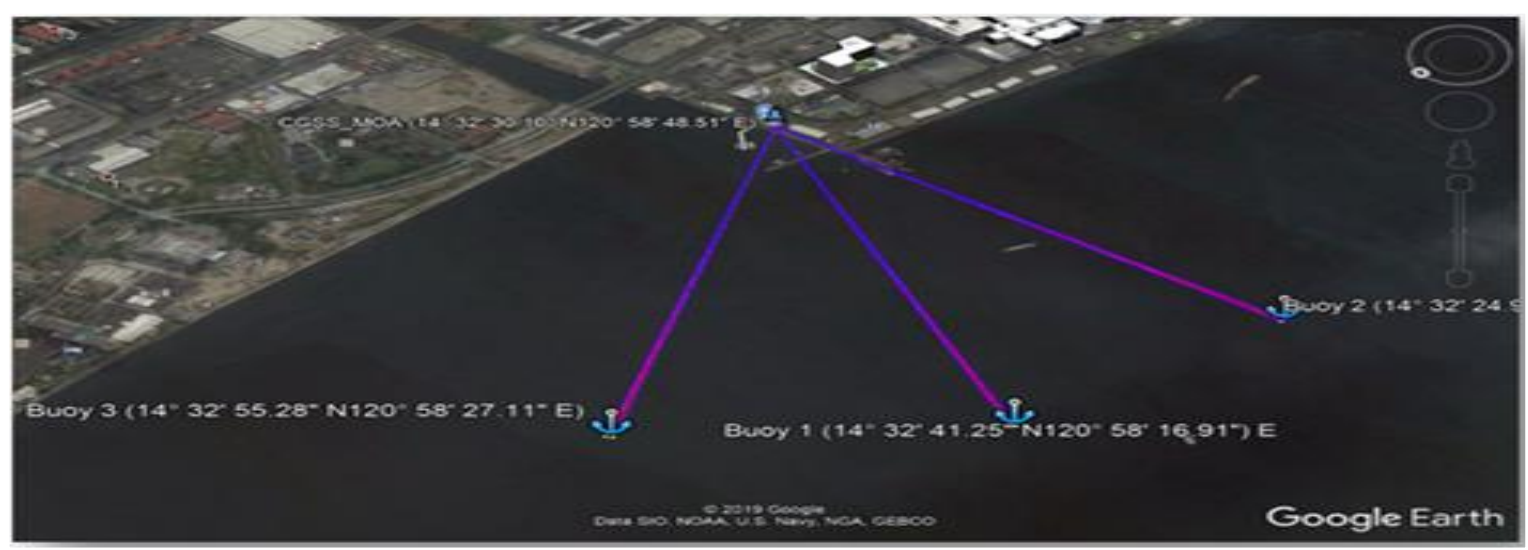

Figure 6 Network topology

The exact location of the weather buoys is as follows:

1 Longitude: $14^{\circ} 32^{\prime} 41.25^{\prime \prime} \mathrm{N}$

Latitude: $120^{\circ} 58^{\prime} 16.91^{\prime \prime} \mathrm{E}$

$$
\text { Range: } 1000 \mathrm{~m}
$$

Heading: $0.000000^{\circ}$

Tilt: $45.000000^{\circ}$

2 Longitude: $14^{\circ} 32$ '24.94" $\mathrm{N}$

Latitude: $120^{\circ} 58^{\prime} 15.78^{\prime \prime} \mathrm{E}$

Range: $1000 \mathrm{~m}$

Heading: $0.000000^{\circ}$

Tilt: $45.000000^{\circ}$

3Longitude: $14^{\circ} 32 ' 55.28^{\prime \prime} \mathrm{N}$

Latitude: $120^{\circ} 58^{\prime} 27.11^{\prime \prime} \mathrm{E}$

Range: $1000 \mathrm{~m}$

Heading: $0.000000^{\circ}$

Tilt: $45.000000^{\circ}$

Base Station

Longitude: $14^{\circ} 32^{\prime} 30.10^{\prime \prime} \mathrm{N}$

Latitude: $120^{\circ} 58^{\prime} 48.51^{\prime \prime} \mathrm{E}$

Range: $0 \mathrm{~m}$

Heading: $0.000000^{\circ}$

Tilt: $45.000000^{\circ}$

Figures 7 to 13 show the graphical representations of data from the monitoring sensors of the weather buoy that collects the following meteorological and hydrological parameters.

- Air Temperature

- Air Pressure

- Liquid Precipitation

- Moisture in the Air

- Salinity of Liquids

- Solar Irradiance

- Water Temperature

- Wind Speed and Direction
This is done through the use of Huffman Coding in compression of data in the transmitter end and Huffman Coding in decompression of data at the receiving end. There are twenty collected data of each sensor that are used in these graphical representations.

The anemometer data shows the speed of the wind as well as the direction. A commonly used instrument for monitoring the weather environment. The data is collected in the meteorological part of the buoy (Figure 7). Barometer is used to measure the air pressure. Barometers make accurate predictions when combined with wind observations (Figure 8). A rain gauge is an instrument used to collect and measure the amount of rainfall. It measures the liquid precipitation within a period of time over an area (Figure 9). Relative humidity is the amount of water vapor in air or the moisture content in the atmosphere. It is expressed in percentage that specifies the amount of moisture that can be held by air or the atmosphere (Figure 10). Salinity is the amount of salt dissolved in water or refers to the concentration of salts in water. Salinity is an important factor in monitoring natural waters as it is vital for the life of animals and also of aquatic plants (Figure 11). The solar radiation data is the measurement of radiated solar energy. It is collected through the use of solar panel. It serves as the alternative power source of the buoy and contributes to monitoring of weather (Figure 12). The water temperature data is the measurement of the temperature of the sea which contributes to the monitoring and forecasting of the weather. It is collected through the use of a sensor that is in the hydrological part of the buoy (Figure 13). The air temperature data is the measurement of the temperature of the air which is a factor in weather monitoring and weather forecasting. The data is 
Jessica S. Velasco et al.

collected through the use of a sensor that is in the meteorological part of the buoy (Figure 14).
A part of the buoy that is submerged in water is called hydrological part. A part of the buoy that is above the water is called the meteorological part.

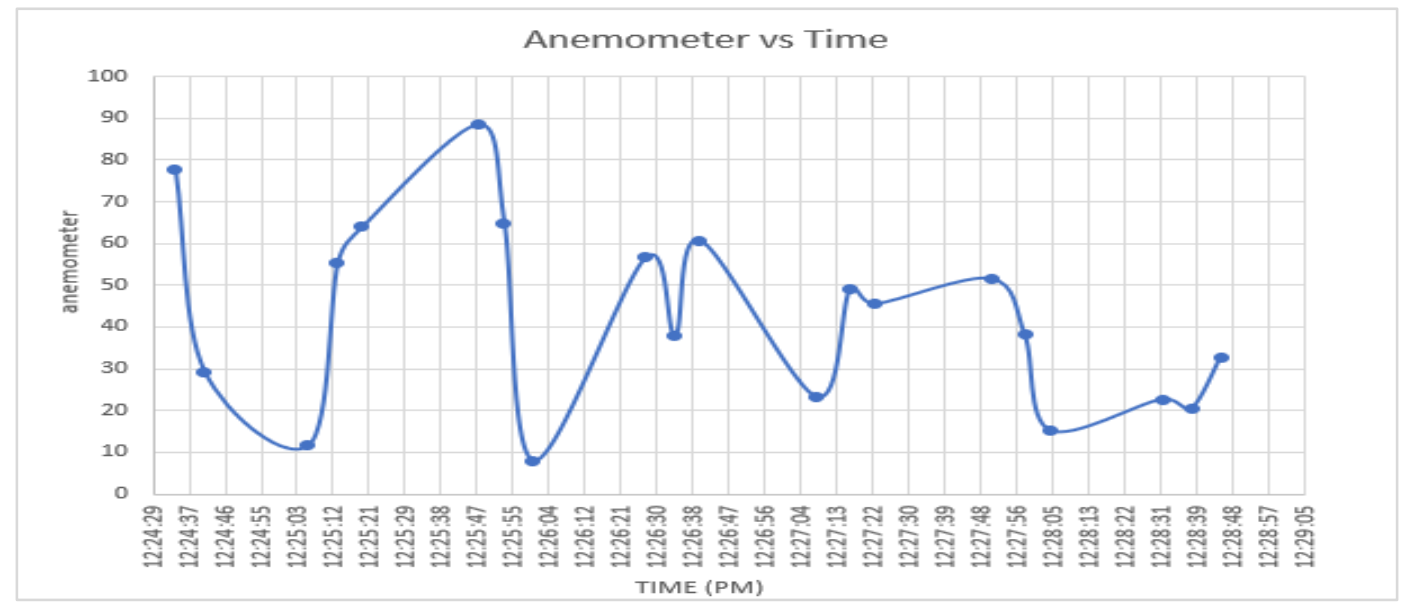

Figure 7 Anemometer data

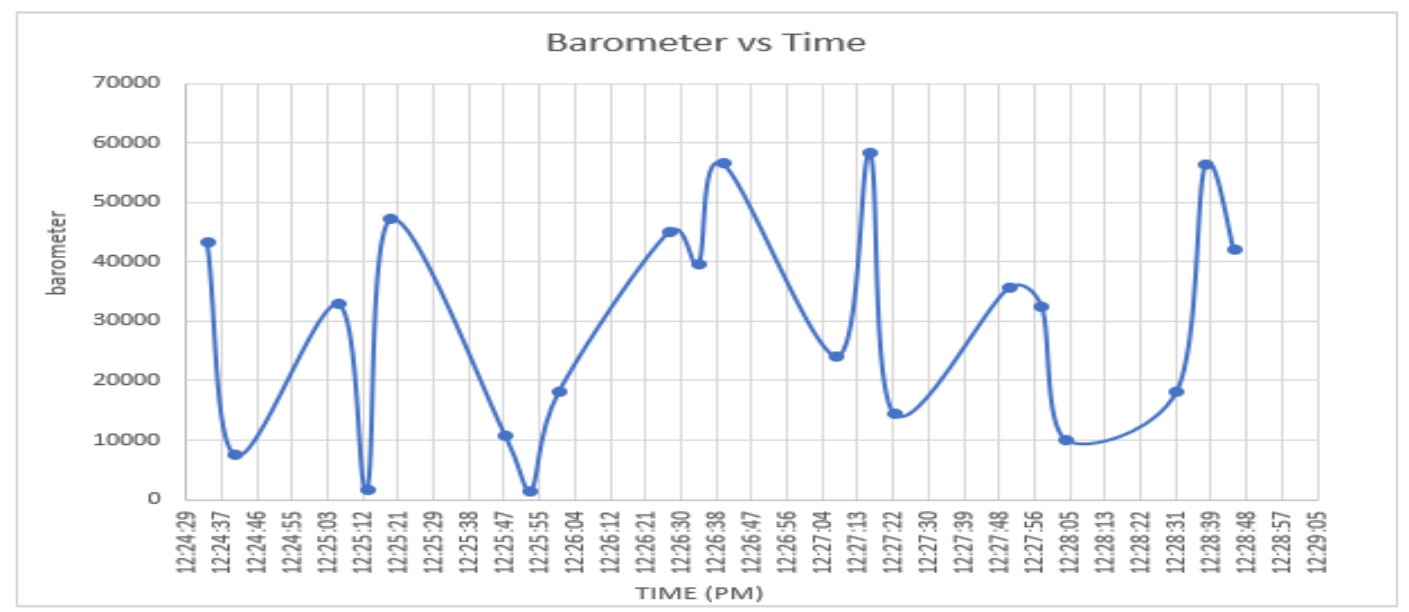

Figure 8 Barometer data

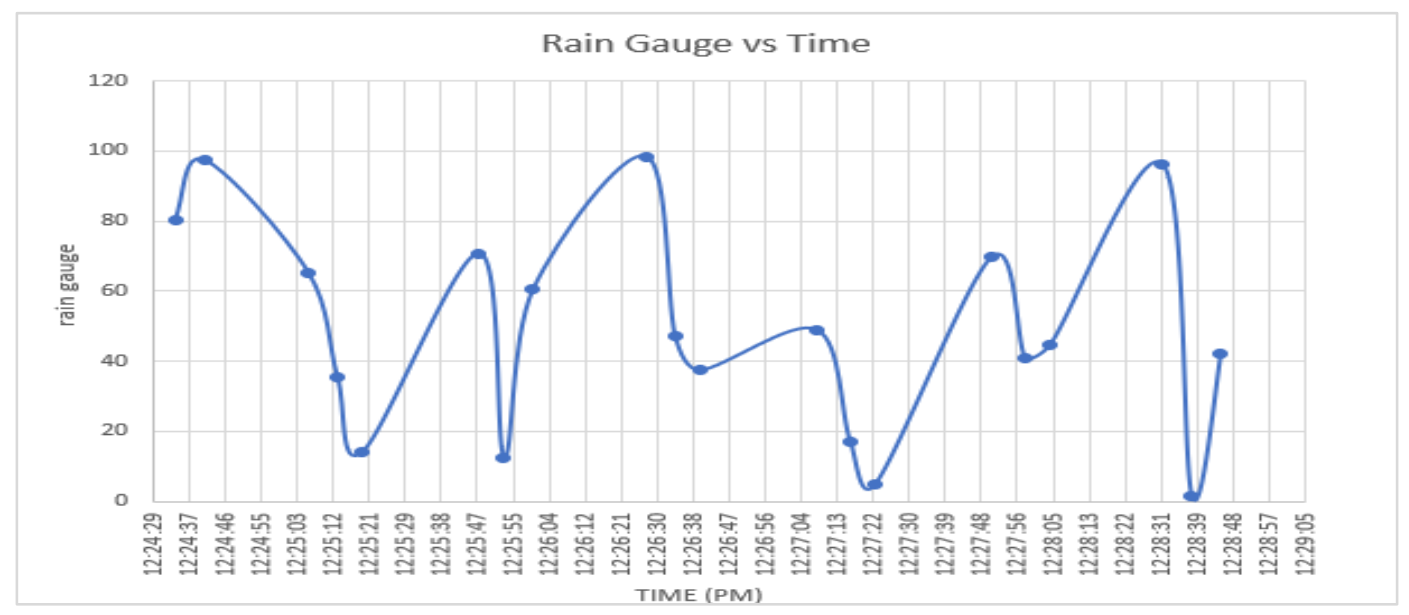

Figure 9 Rain gauge data 


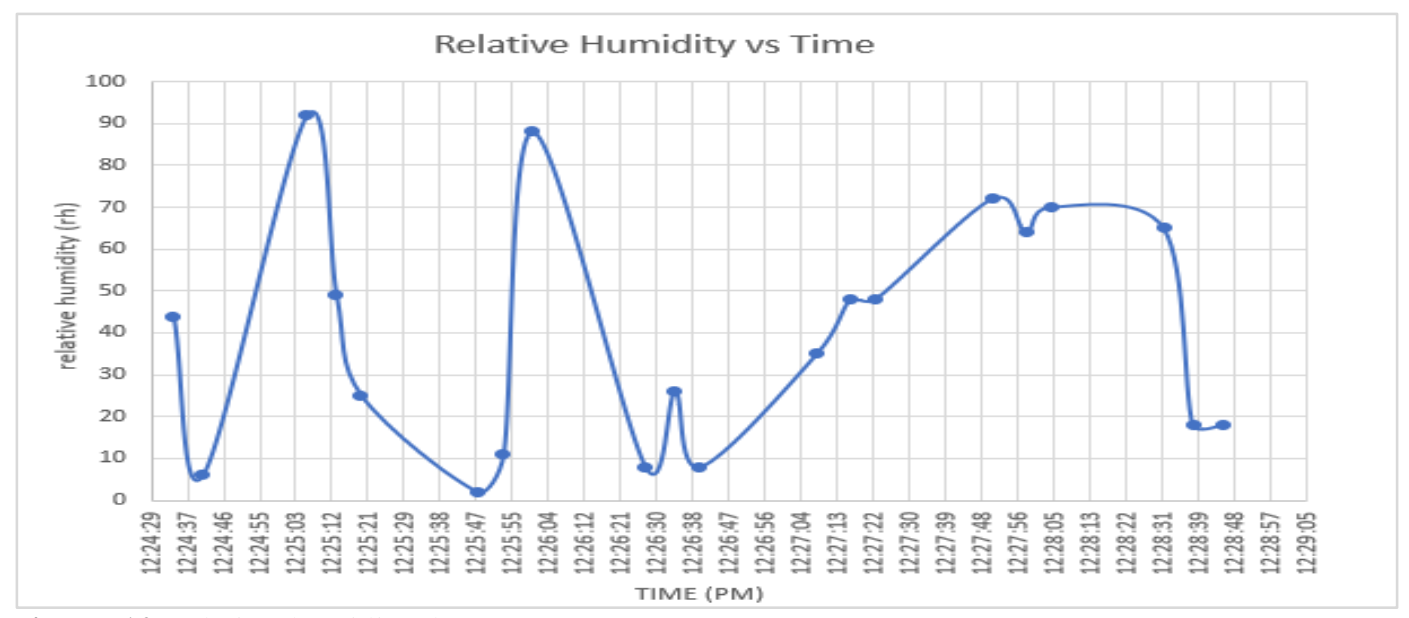

Figure 10 Relative humidity data

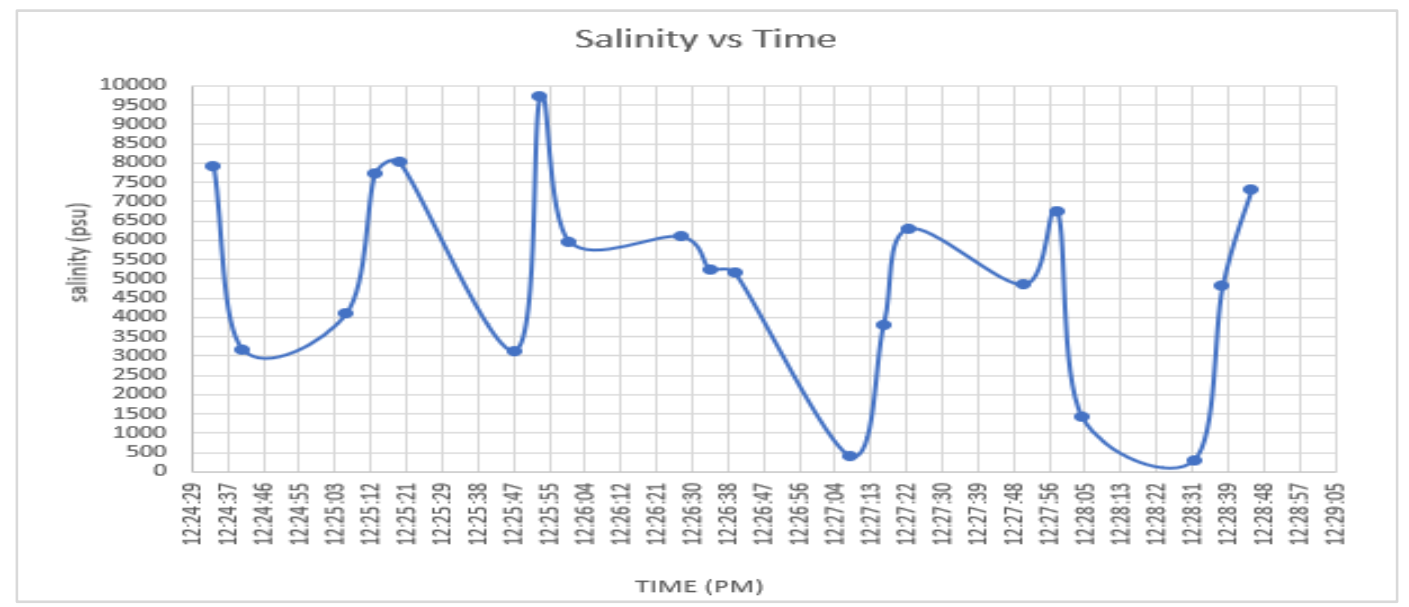

Figure 11 Salinity data

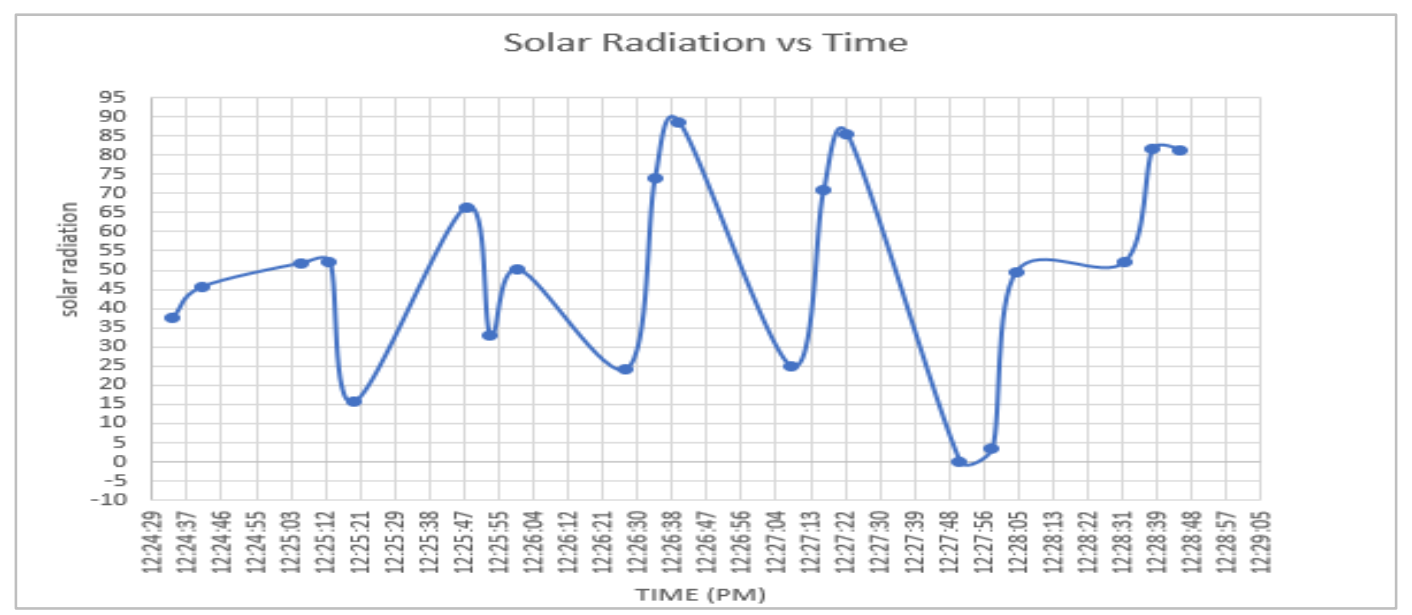

Figure 12 Solar radiation data 


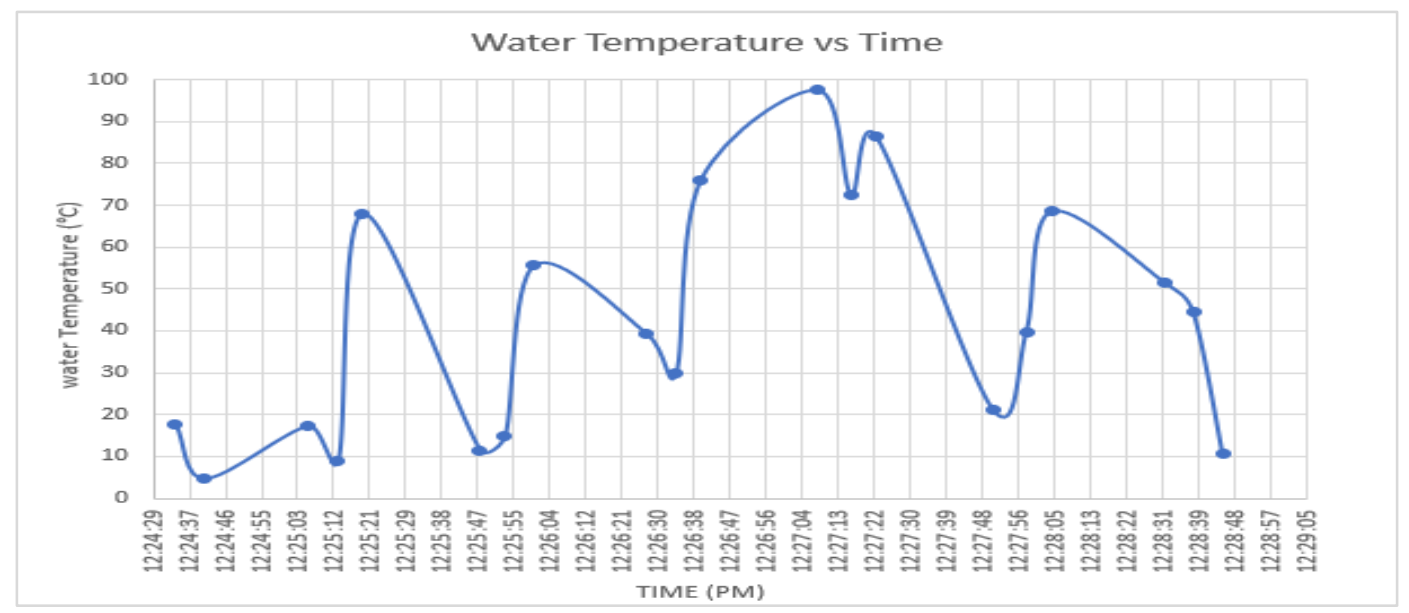

Figure 13 Water temperature data

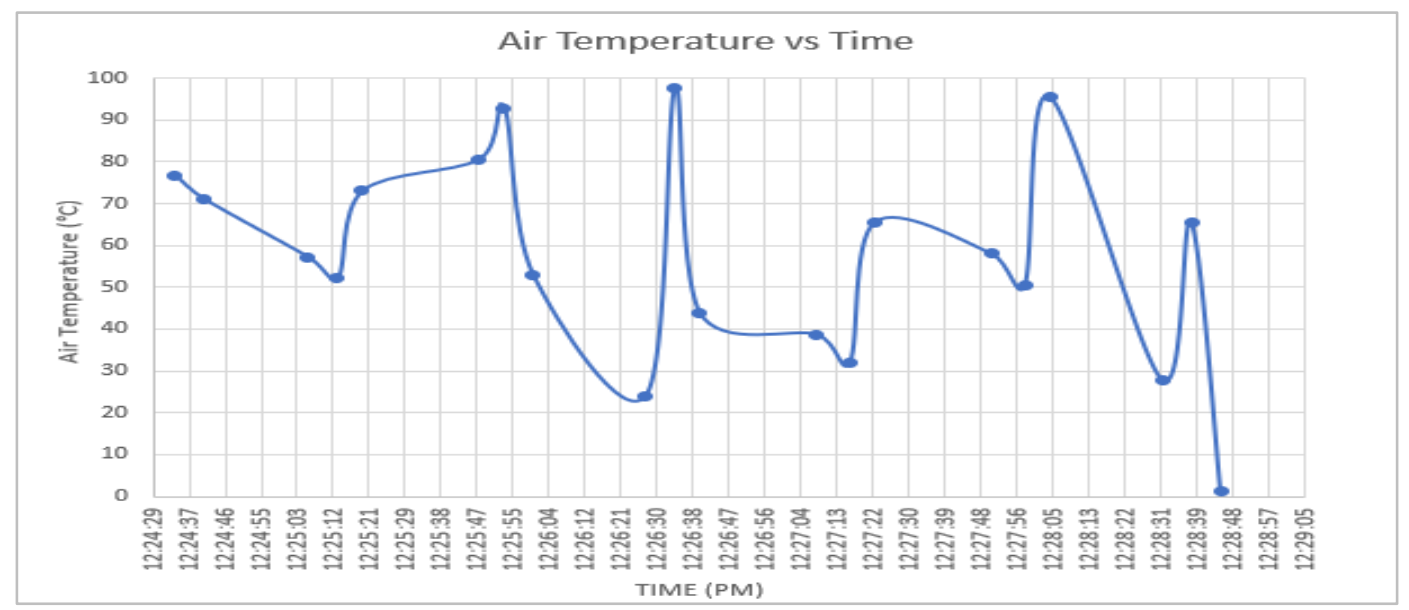

Figure 14 Air Temperature data

In this study the transmission of data from the sensors in the weather buoy was compressed and decompressed successfully through the LoRa communication. The evaluated result has 125 transmissions with 7 non compressed data. This gives the text file compression of 118 out of 125 or $94.4 \%$ accuracy. The use of Huffman Coding in compression and decompression is successfully implemented. It is also depicted from Figures 7 to 14. Another finding of the study is about the time delay in the use of Huffman Coding in terms of compression. The time delay of compression is 13 minutes and 20 seconds before it is received at the main BS. For the non-compressed data, the time delay is 6 minutes and 8 seconds before being received at the main base. Complete list of abbreviations is shown in Appendix I.

\section{Conclusion and future work}

The weather buoys are equipped with LoRa communication technology. Through this technology, the range capacity for the transmission of data is widened. It can now be deployed at least $1 \mathrm{~km}$ away from the shore. It does not require internet connection as it has its own server. The data gathered from the weather buoys are transmitted to the organized database created by the proponents. The proponents were able to design a solution to create a LoRa communication technology wirelessly for weather buoys. In this research, the proponents were able to create a solution for a LoRa Communication technology wirelessly for weather buoys.

Also, the proponents were able to create an algorithm for the compression and decompression of data. The digital signal processing method used is Huffman Coding. It is concluded that Huffman Coding is an efficient source-coding algorithm and it produces the smallest number of code symbols possible for a single source symbol. It is an optimal data transfer solution that can compress the data up to $94.4 \%$. The 
proponents successfully reduced the bit size of the collected data.

With the comparative evaluation done on both compressed and non-compressed data, it was evident that compressing data using Huffman coding give significantly faster time for the main base to receive the transmitted input data. Compressed data using Huffman coding can be sent within 13 seconds while for non-compressed data it would take more than 6 minutes plus the fact that there are data that failed to reach the end due to data traffic. Even with the fact the it helps in the compression and transmitting data in quicker time. It cannot be considered to be suitable for real-time transmission and monitoring of weather parameters but it can possibly play a large role in other ways in this field.

For future work, this study can be used to help other researchers in expanding the studies about the use of source coding in data transmission. The compression and decompression technique used here can also be modified. So that it can be used for greater outcomes in future studies of data transmission using source coding. To add, an improvement on the design as well as on the source coding, or using other compression techniques can improve the time delay. It may be suitable for real-time transmission and monitoring for weather buoy systems.

\section{Acknowledgment}

The authors would like to express their gratitude to the Philippine Coast Guard led by Capt. Glen B. Daraug, commanding officer of Barko Republika ng Pilipinas Cape Engaño (MRRV 4411). LCDR. Rockliff C. Bulling. CGSSCCP station commander and the MSSC office, for sharing their knowledge and resources to fulfill this study. Also, the authors would like to express their gratitude to Mr. Andrew Stephen Nacion for always giving a helping hand.

This study is partially supported by the University Research and Development Services, Office of the Technological University of the Philippines.

Conflicts of interest

The authors have no conflicts of interest to declare.

\section{References}

[1] Adyanti DA, Asyhar AH, Novitasari DC, Lubab A, Hafiy usholeh M. Forecasts marine weather on java sea using hybrid methods: TS-ANFIS. In international conference on electrical engineering, computer science and informatics 2017 (pp. 1-6). IEEE.

[2] Bor MC, Roedig U, Voigt T, Alonso JM. Do LoRa lowpower wide-area networks scale? In proceedings of the ACM international conference on modeling, analysis and simulation of wireless and mobile systems 2016 (pp. 59-67).

[3] Devalal S, Karthikey an A. LoRa technology-an overview. In international conference on electronics, communication and aerospace technology 2018 (pp. 284-90). IEEE.

[4] Samara G, Al-okour M. Optimal number of cluster heads in wireless sensors networks based on LEACH. International Journal of Advanced Trends in Computer Science and Engineering. 2020; 9(1): 891-5.

[5] Cruz RT, Tolentino LK, Juan RS, Kim HS. IoT-based monitoring model for pre-cognitive impairment using $\mathrm{pH}$ level as analyte. International Journal of Engineering Research and Technology. 2019; 12(5):711-8.

[6] Tolentino LK, Cruz RT, Raguindin EQ. Cognitive impairment monitoring system via long range (LoRa) low-power wireless communication using $\mathrm{pH}$ level. Basic \& Clinical Pharmacology \& Toxicology. 2019; 125(S9):32-3.

[7] Tolentino LK, De Pedro CP, Icamina JD, Navarro JB, Salvacion LJ, Sobrevilla GC, et al. Development of an IoT-based intensive aquaculture monitoring system with automatic water correction. International Journal of Computing and Digital Systems. 2020; 9:1-11.

[8] Tolentino LK, Chua EJ, Añover JR, Cabrera C, Hizon CA, Mallari JG, et al. IoT-Based automated water monitoring and correcting modular device via LoRaWAN for aquaculture. International Journal of Computing and Digital Systems. 2021; 10(1):533-44.

[9] Tolentino LK, De Pedro CP, Icamina JD, Navarro JB, Salvacion LJ, Sobrevilla GC, et al. Weight prediction system for nile tilapia using image processing and predictive analysis. International Journal of Advanced Computer Science and Applications. 2020; 11(8):399406.

[10] Arago NM, Galido EA, Padilla MV, Tulin LM, Virrey GC, Velasco JS. Long range communication technology for weather buoy. International Journal of Emerging Trends in Engineering Research. 2020; 8(8):4399-404.

[11] Bedruz RA, Quiros AR. Comparison of huffman algorithm and lempel-ziv algorithm for audio, image and text compression. In international conference on humanoid, nanotechnology, information technology, communication and control, environment and management 2015 (pp. 1-6). IEEE.

[12] Moffat A. Huffman coding. ACM Computing Survey s (CSUR). 2019; 52(4):1-35.

[13] Sivanantham E. Base station positioning in wireless networks using self-adaptive particle swarm optimization approach. International Journal of Advanced Trends in Computer Science and Engineering. 2020; 9(2):1662-7.

[14] Doloi A, Barkataki N, Saikia M, Saikia D. Development of a wireless sensor network based smart multiple ambient conditions sensing system for the rearing process of eri silkworm. International Journal of Advanced Technology and Engineering Exploration. 2019; 6(52):50-60. 
[15] San-Um W, Lekbunyasin P, Kodyoo M, Wongsuwan W, Makfak J, Kerdsri J. A long-range low-power wireless sensor network based on U-LoRa technology for tactical troops tracking systems. In third Asian conference on defence technology (ACDT) 2017 (pp. 32-5). IEEE.

[16] Rizzi M, Ferrari P, Flammini A, Sisinni E, Gidlund M. Using LoRa for industrial wireless networks. In international workshop on factory communication systems 2017 (pp. 1-4). IEEE.

[17] Cho H, Yu SC. Development of a long-range marine communication system for fishery buoy searching. In OCEANS MTS/IEEE Charleston 2018 (pp. 1-5). IEEE.

[18] Chande, SV. Database query optimization using genetic algorithms: a systematic literature review. International Journal of Advanced Trends in Computer Science and Engineering. 2019; 8(5):1903-13.

[19] Llorente CA, Ang JO, Chan Shio KR, Chua JE, Cu EI. Implementation of a web based weather monitoring station and data storage sy stem. International Journal of Advanced Trends in Computer Science and Engineering. 2019; 8(3):527-30.

[20] Zhang Z, Miao P, Lu H, Hu K, Li F, Jin G. A low-power DAQ system with high-speed storage for submersible buoy. In international conference on electronics technology 2019 (pp. 400-3). IEEE.

[21] Gopal J, Vellingiri J, Gitanjali J, Arivuselvan K, Sudhakar S. An improved trusted on-demand multicast routing with QoS for wireless networks. International Journal of Advanced Trends in Computer Science and Engineering. 2020; 9(1):261-5

[22] Kumar S, Patidar K, Kushwah R, Chouhan S. A review and analysis on text data encryption techniques. International Journal of Advanced Technology and Engineering Exploration. 2017; 4(30):88-92.

[23] Sinde R, Kaijage S, Njau K. Cluster based wireless sensor network for forests environmental monitoring. International Journal of Advanced Technology and Engineering Exploration. 2020; 7(63):36-47.

[24] Alotaibi N. An efficient technique for reducing transmission energy of sensor node to enhance the lifetime of the WSN's. International Journal of Advanced Trends in Computer Science and Engineering. 2019; 8(2):108-11.

[25] Parmar J, Nagda T, Palav P, Lopes H. IOT based weather intelligence. In international conference on smart city and emerging technology 2018 (pp. 1-4). IEEE.

[26] Ishibashi K, Yamaoka K. A study of network stability on wireless sensor networks. In 9th international conference on next generation mobile applications, services and technologies 2015 (pp. 96-101). IEEE

[27] Li Y, Zhang Z, Huangfu W, Chai X, Zhu X, Zhu H. Sea route monitoring sy stem using wireless sensor network based on the data compression algorithm. China Communications. 2014; 11(13):179-86.

[28] Lambebo A, Haghani S. A wireless sensor network for environmental monitoring of greenhouse gases. In proceedings of the ASEE Zone I conference. University of Bridgeport, Bridgpeort, CT 2014.
[29] Huebner C, Cardell-Oliver R, Hanelt S, Wagenknecht $\mathrm{T}, \mathrm{M}$ onsalve A. Long-range wireless sensor networks with transmit-only nodes and software-defined receivers. Wireless Communications and Mobile Computing. 2013; 13:1499-510.

[30] Alkandari A, Alabduljader Y, Moein SM. Water monitoring system using wireless sensor network (wsn): case study of Kuwait beaches. In international conference on digital information processing and communications 2012 (pp. 10-5). IEEE.

[31] Munandar A, Fakhrurroja H, Rizqy awan MI, Pratama RP, Wibowo JW, Anto IA. Design of real-time weather monitoring system based on mobile application using automatic weather station. In international conference on automation, cognitive science, optics, micro electromechanical system, and information technology 2017 (pp. 44-7). IEEE.

[32] Yamanouchi M., Ochiai H., Reddy Y.K., Esaki H. Sunahara H. Case study of constructing weather monitoring system in difficult environment. In $11^{\text {th }}$ international conference on ubiquitous intelligence and computing 2014 (pp. 692-6). IEEE.

[33] Majumdar I, Banerjee B, Preeth MT, Hota MK. Design of weather monitoring system and smart home automation. In international conference on system, computation, automation and networking 2018 (pp. 15). IEEE.

[34] Khotimah PH, Munandar D. Data center for integrating weather monitoring systems. In international conference on computer, control, informatics and its applications 2013 (pp. 279-84). IEEE.

[35] Kodali RK, Borra KY, Gn SS, Domma HJ. An IoT based smart parking system using LoRa. In international conference on cyber-enabled distributed computing and knowledge discovery 2018 (pp. 151-3). IEEE.

[36] Hay ati N, Sury anegara M. The IoT LoRa sy stem design for tracking and monitoring patient with mental disorder. In international conference on communication, networks and satellite 2017 (pp. 1359). IEEE.

[37] Li Y, Yan X, Zeng L, Wu H. Research on water meter reading system based on LoRa communication. In international conference on smart grid and smart cities 2017 (pp. 248-51). IEEE.

[38] Chou YS, Mo YC, Su JP, Chang WJ, Chen LB, Tang JJ, et al. I-car system: a LoRa-based low power wide area networks vehicle diagnostic system for driving safety. In international conference on applied system innovation 2017 (pp. 789-91). IEEE.

[39] Xue-fen W, Xing-jing D, Yi Y, Jing-wen Z, Sardar MS, Jian C. Smartphone based LoRa in-soil propagation measurement for wireless underground sensor networks. In conference on antenna measurements \& applications 2017 (pp. 114-7). IEEE.

[40] Nakamura M, Takeno K. Green base station using robust solar system and high performance lithium ion battery for next generation wireless network $(5 \mathrm{G})$ and against mega disaster. In international power electronics conference 2018 (pp. 201-6). IEEE. 
[41] Sun H, Ding C, Yang T, Guo YJ, Qin P. A wideband base station antenna with stable radiation pattern. In Australian microwave symposium 2018 (pp. 5-6). IEEE.

[42] Huang H, Liu Y, Gong S. A broadband dual-polarized base station antenna with sturdy construction. IEEE Antennas and Wireless Propagation Letters. 2016; 16:665-8.

[43] Latiff NA, Ismail IS. Performance of mobile base station using genetic algorithms in wireless sensor networks. In German microwave conference 2016 (pp. 251-4). IEEE.

[44] Chu QX, Zheng DZ, Wu R. Multi-array multi-band base-station antennas. In international workshop on antenna technology: small antennas, innovative structures, and applications 2017 (pp. 137-9). IEEE.

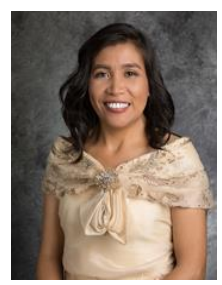

Jessica S. Velasco is an Assistant Professor in the Department of Electronics Engineering at the Technological University of the Philippines. She is a Regular Member in the National Research Council of the Philippines (NRCP). She has 17 years of teaching/research. She graduated with a Master's degree in Electronics Engineering at Gokongwei College of Engineering in De La Salle University (DLSU), Manila. Presently, she is taking up her PhD in Electronics Engineering in DLSU, also. Her areas of interest include Artificial Intelligence, Statistics and Machine Learning. Email: jessica_velasco@tup.edu.ph

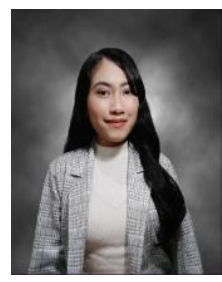

Mariela Credo, graduated elementary and high school at San Dionisio Elementary School at Parañaque City and Araullo High School at Manila CIty. She finished 3 years of Bachelor of Technology in Electronics Engineering Technology (2014-2017) before shifting to Bachelor of Science in Electronics Engineering, both taken in Technological University of the Philippines - Manila. She is an active member of the Institute of Electronics Engineers of the Philippines (IECEP) and TUP Manila's Organization of Electronics Engineering Students (OECES).

Email: mariela.credo@tup.edu.ph

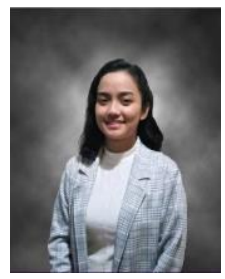

Abeille Mae P. Salazar finished her primary and secondary education at Infant Jesus Montessori Center. She took a Bachelor of Technology in Electronic Communications Engineering Technology degree program for three years and shifted to Bachelor of Science in Electronics Engineering at Technological University of the Philippines, Manila. In 2019, she passed the Electronics Technician board exam. She is also an active member of Organization of Electronics Engineering Students (OECES) in TUP -

Manila and Institute of Electronics Engineers of the Philippines (IECEP).

Email: abeillemae.salazar@tup.edu.ph

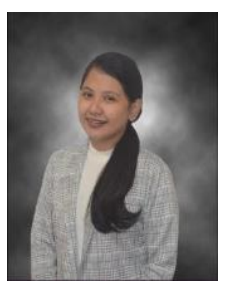

Shirleen Rence S. De Ocampo finished her Bachelor of Technology in Electronics Technology at Technological University of the Philippines, Taguig and currently taking Bachelor of Science in Electronics Engineering at Technological University of the Philippines, Manila. She worked as an engineering tech at ONSEMI INC. She is a licensed Electronics Technician and an active member of the Institute of Electronics Engineers of the Philippines (IECEP).

Email: shirleenrence.deocampo@tup.edu.ph

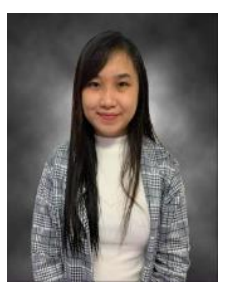

Venice Julliane C. Enriquez finished her primary and secondary education at Our Lady of Guadalupe Montessori School and St. Michael School of Cavite. She is a graduate of Electronics Engineering Technology, a 3-year vocational course at Technological University of the Philippines-Cavite. She is currently pursuing Bachelor of Science in Electronics Engineering at Technological University of the PhilippinesManila, and an active member of school organizations, OECES and IECEP.

Email: venicejulliane.enriquez@tup.edu.ph

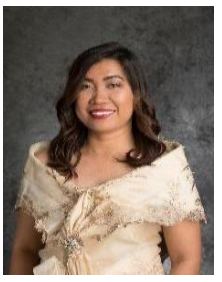

Maria Victoria C. Padilla is currently a Faculty Member of the Department of Electronics Engineering at Technological University of the Philippines. She graduated MS in Electronics Engineering major in Microelectronics at the Mapua University. She is currently one of the members of the Technical Committee on Cleanrooms (TC 83) of the Bureau of Product Standards of the Philippines' Department of Trade and Industry. Her areas of interest include Biomedical Engineering and Sensor Systems. Email: mariavictoria_padilla@tup.edu.ph

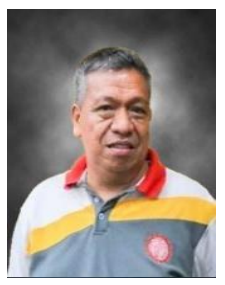

Design.

Email: edgar_galido@tup.edu.ph
Edgar A. Galido is currently a Faculty Member of the Department of Electronics Engineering at Technological University of the Philippines-Manila. He graduated Electronics Engineering at Cebu Institute of Technology. His area of interests are Electronics System and 


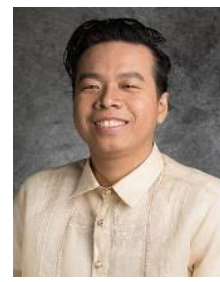

Nilo M. Arago is an Associate Professor II and a Faculty Member of the Electronics Engineering Department at the Technological University of the Philippines - Manila. He is currently the College Secretary of the College of Engineering (COE), TUP, and Graduate Program Coordinator. He is presently a Regular Member in the National Research Council of the Philippines. His areas of interest include Neural Networks, ANFIS, and Signal Processing.

Email: nilo_arago@tup.edu.ph

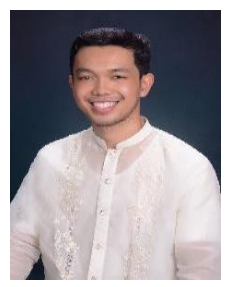

Glenn C. Virrey is an alumnus and a Faculty Member of the Electronics Engineering Department at the Technological University of the Philippines - Manila. He is currently taking his Master's degree major in Microelectronics at the Mapua University and has his early career years in the corporate industry as an Apprentice Failure Analy sis Engineer and Supplier Quality Engineer.

Email: glenncalvin_virrey@tup.edu.ph

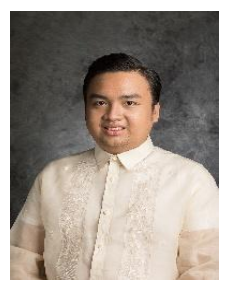

Lean Karlo S. Tolentino was the Head of the Department of Electronics Engineering, Technological University of the Philippines (TUP) in M anila from 2017 to 2019. He is currently the director of the University Extension Services Office and Assistant Professor at TUP since 2019. He has a BS degree in Electronics and Communications Engineering from TUP and $\mathrm{MS}$ in Electronics Engineering major in Microelectronics from Mapua, University. He is currently pursuing his $\mathrm{PhD}$ in Electrical Engineering at National Sun Yat-Sen University. He is one of the members of the Technical Committee on Audio, Video, and Multimedia Equipment (TC 59) and Technical Committee on Electromagnetic Compatibility (TC 74) of the Bureau of Product Standards of the Philippines' Department of Trade and Industry. $\mathrm{He}$ is a Regular Member of the National Research Council of the Philippines. His research interests include Microelectronics and Information and Computing Technologies.

Email: leankarlo_tolentino@tup.edu.ph

\begin{tabular}{|c|c|c|}
\hline \multicolumn{3}{|c|}{ Appendix I } \\
\hline S.No. & Abbre viation & Description \\
\hline 1 & API & Application Programming Interface \\
\hline 2 & ASK & Asynchronous Shift Keying \\
\hline 3 & ATPCVQ & $\begin{array}{l}\text { Adaptive TimePiecewise Constant } \\
\text { Vector Quantization }\end{array}$ \\
\hline 4 & AWS & Aut omated Weather Station \\
\hline 5 & BS & Base Station \\
\hline 6 & $\mathrm{CH}$ & Cluster's Head \\
\hline 7 & DAQ & Data Acquisition \\
\hline 8 & DW & Data Warehouse \\
\hline 9 & GPS & Global Positioning System \\
\hline 10 & HTX & HTML Extension \\
\hline 11 & IITH & $\begin{array}{l}\text { Indian Institute of T echnology } \\
\text { Hyderabad City }\end{array}$ \\
\hline 12 & IMD & Indian Meteorological Department \\
\hline 13 & IoT & Internet of Things \\
\hline 14 & LoRa & Long Range \\
\hline 15 & $\mathrm{LiB}$ & Lithium-ion Battery \\
\hline 16 & LoRaWAN & Long Range Wide Area Net work \\
\hline 17 & LPWAN & Low Power Wide Area Net work \\
\hline 18 & MMS & Multimedia Message Service \\
\hline 19 & MySQL & My Structured Query Language \\
\hline 20 & OBD & On-board Diagnostics \\
\hline 21 & $\mathrm{pH}$ & Potential of Hydrogen \\
\hline 22 & PHP & Hypertext Preprocessor \\
\hline 23 & PSU & Practical Salinity Unit \\
\hline 24 & PV & Photovoltaic \\
\hline 25 & RF Modem & $\begin{array}{l}\text { Radio Frequency Modulator } \\
\text { Demodulator }\end{array}$ \\
\hline 26 & SMS & Short Message Service \\
\hline 27 & STM81151 G & ST's Low-Energy Microcontroller \\
\hline 28 & SWR & Standing Wave Ratio \\
\hline 29 & UHF & Ultra-High Frequency \\
\hline 30 & U-LoRa & $\begin{array}{l}\text { Universal and Ubiquit ous Long } \\
\text { Range }\end{array}$ \\
\hline 31 & UNHEX & Unhexadecimal \\
\hline 32 & Wi-Fi & Wireless Fidelity \\
\hline 33 & WHO & World Health Organization \\
\hline 34 & WSNs & Wireless Sensor Net works \\
\hline 35 & WUSN & $\begin{array}{l}\text { Wireless Underground Sensor } \\
\text { Network }\end{array}$ \\
\hline 36 & $\mathrm{ZbC}$ & Zone-basedClustering \\
\hline
\end{tabular}

